\title{
Teachers' beliefs about diversity: an analysis from a personal and professional perspective
}

\author{
Esther Chiner ${ }^{1 *}$, María C. Cardona-Moltó2 ${ }^{2}$ José Marcos Gómez Puerta ${ }^{3}$ \\ 1Department of Health Psychology, University of Alicante, Spain \{esther.chiner@ua.es\} \\ 2Department of Health Psychology, University of Alicante, Spain \{cristina.cardona@ua.es\} \\ 32Department of General and Specific Didactics, University of Alicante, Spain \{marcos.gomez@ua.es\}
}

Received on 4 November 2014; revised on 4 November 2014; accepted on 12 November 2014; published on 15 January 2015

DOI: 10.7821/naer.2015.1.113

\begin{abstract}
The purpose of this study was to examine the beliefs that teachers have about diversity and their level of sensitivity towards some topics related to it. Moreover, beliefs were compared according to teachers' personal and professional views and teaching experience. The Personal and Professional Beliefs about Diversity Scales (Pohan and Aguilar, 1999) were administered to a sample of 233 teachers. Results showed highly positive beliefs towards diversity in all its dimensions (cultural, linguistic and social diversity, ability, gender, sexual orientation and religion), especially regarding its personal implications compared to the professional ones. Likewise, it was observed a significant relationship between years of teaching experience and professional beliefs about diversity, so teachers with no school experience showed a higher tolerance than those with teaching experience, mainly in aspects related to cultural, linguistic and social differences, ability and gender. The implications that these results have for educational practice and the need for the development of multicultural education courses that favour an effective teaching are discussed.
\end{abstract}

\section{KEYWORDS: DIVERSITY, TEACHER BELIEFS,} MULTICULTURAL EDUCATION

\section{INTRODUCTION}

In the 21st century, diversity has clearly become recognised as an inherent treat of our socio-cultural and educational environment. Borders dissolve and cultural, social and linguistic differences, among other differences, become obvious in our daily life. Schools do not stay out of this phenomenon to the point that the educational system had to adapt itself to these new values and demands. Diversity is a concept that was not always understood as valuable (Cardona, Jiménez, \& Chiner, 2007). However, nowadays it is one of the mainstays of contemporary societies and current educational system. In general terms, we can define diversity as individual differences produced in and between different groups because of race, ethnicity, religion,

\footnotetext{
*To whom correspondence should be addressed.

Departamento de Psicología de la Salud

Universidad de Alicante

Campus de Sant Vicent del Raspeig

Ap. 99 E-03080 Alicante, Spain
}

language, gender and social class (Banks \& Banks, 2007). In this regard, and according to Fernández Batanero (2003), attention to diversity in schools will try to avoid that differences become inequalities, adapting themselves to students' characteristics and building a curriculum addressed to everybody.

In this new context, teachers must be prepared to teach all the students they have in their classrooms in an effective way. With this purpose, they must acquire not only the necessary knowledge and skills to teach students from different cultural, linguistic, religious and gender backgrounds, but a belief system that values difference and supports all learners (Pohan, Ward, Kouzekanani, \& Boatright, 2009). Beliefs are representative bits of information that a person has about an object, person or group of individuals based on certain facts or personal opinions (Ajzen \& Fishbein, 1980). Dealing with diversity is a challenge for teachers whose beliefs, attitudes and perceptions will determine their educational response. In this regard, Bandura (1982) states that beliefs guide both knowledge and action and therefore they act like filters affecting instructional practices and interactions. Beliefs, attitudes and expectations lead and guide teachers' responses towards diverse learners (Giambo \& Szecsi, 2007; Nespor, 1987; Pajares, 1992). Thus, Brookhart and Freeman (1992) talk about the domino effect to refer to the impact that teachers' beliefs have on student's learning. According to these authors, beliefs lead to certain ideas and decisions that impact on teachers' actions which, at the same time, influence students' achievement. Understanding this process can help teachers to improve their knowledge about students' diversity and their educational practices (Brookhart \& Freeman, 1992).

Richardson (1996) suggests that teachers' belief system is well established by the time they enter college. Their cultural and social background, previous experiences and personal features impact on their actions, even when they are no aware of it. Therefore, for teachers to be able to recognise and understand these beliefs in order to achieve positive changes (Bryan, 2003), it is important to identify them. Hence, the more aware of their belief system teachers are, the more they will be able to influence on their own actions and interactions (Su-Chuan, 2009), and the more they will let students to overcome the barriers that prevent them from experiencing equal academic opportunities. However, the research carried out so far does not reach conclusive results. On the one hand, some studies show that teachers are sensitive towards diversity (e.g., Cardona, 2005; Cardona \& Chiner, 2002; Milner, Flowers, Moore, Moore, 
\& Flowers, 2003), while others state neutral or negative beliefs (Hansman, Jackson, Grant, \& Spencer, 1999; Larke, 1990). These inconsistent results suggest a need for further research in this area.

On the other hand, research on beliefs about diversity has been focused on issues related to cultural and ethnic differences (Neuharth-Pritchett, Reiff, \& Pearson, 2001), and has forgotten other aspects like gender, socioeconomic status, ability, language or religion. In this study we try to go further by analysing teachers' beliefs in a wide scope using the model presented by Pohan and Aguilar (2001). This model, apart from understanding diversity from a point of view that includes any sociocultural group historically marginalised, it considers a twodimensional approach (personal and professional) to evaluate teachers' beliefs on diversity. Personal beliefs would be related to the vision that teachers have about the personal world; better said, opinions, expectations or judgements that a person considers as true in his daily life context (e.g., personal relations, children upbringing, relations with other people, life conditions and collective stereotypes). Professional beliefs in this particular case would refer to issues related to schooling (e.g., instructional practices, educational resources, inclusive education). According to the authors, it is necessary to evaluate beliefs from both perspectives because, in some cases, these beliefs can come into conflict. While for some dimensions it can be shown high tolerance from a personal point of view, this could not happen professionally. Previous research carried out to analyse the relationships between both perspectives, personal and professional, show a significantly positive relationship (Pohan, 1994; Schroeder, 2005). A person with a high personal sensitivity towards diversity is more likely to develop professional beliefs and behaviours culturally relevant than others with low sensitivity. However, and in spite of this relation between the two dimensions, previous research also shows significant differences between both belief systems. Studies like those conducted by Su-Chuan (2009) and Shroeder (2005) suggest a greater tolerance towards diversity in the personal context than in the professional one. Nevertheless, in a study carried out by Cardona (2005), participants seemed to show a higher acceptance of diversity issues professionally than personally. These contradictory results reflect the need of going more deeply into this matter. Identifying and recognising the gap between personal and professional beliefs will be useful as a starting point for intervention to promote teachers' professional acceptance of student diversity (Schroeder, 2005).

Likewise, most of the studies about the topic have been carried out with pre-service teachers with the purpose of analysing the impact of multicultural education on teachers' personal and professional beliefs (e.g., Giambo \& Szecsi, 2007; Romine, 2010; Su-Chuan, 2009). The current research also includes in-service teachers, in order to study the possible changes in teachers' beliefs produced by teaching experience. Studies like the one conducted by Cardona (2005) seem to show that teachers with little or none experience tend to have more favourable beliefs about diversity.

In light of the aforementioned, the purpose of this study was to explore and compare teachers' beliefs on diversity from a personal and professional perspective and the impact of teaching experience on these beliefs. Specifically, we tried to answer the following questions:

(1) What are teachers' personal and professional beliefs about diversity?
(2) What level of sensitivity do teachers show about certain diversity issues?

(3) Are there any differences between teachers' personal and professional beliefs on diversity?

(4) Do personal and professional beliefs about diversity differ depending on teaching experience?

\section{METHODOLOGY}

\subsection{Type of research}

A non-experimental quantitative research was carried out, based on a survey design. The aim of the survey was to identify teachers' personal and professional beliefs about diversity and the impact of school experience.

\subsection{Participants}

In the study, 233 teachers from the province of Alicante, Spain, participated voluntarily. Forty of them were males (17\%) and 193 female (83\%). Their ages ranged between 21 and 62 years old, with an average age of 33.7 years $(S D=10.8)$. The sample consisted of $68 \%$ in-service $(n=158)$ and $32 \%$ pre-service teachers $(n=75)$. Therefore, the average years of teaching experience was 8.7 years $(S D=9.25)$.

As for the initial training and the teaching level, $84 \%$ of the participants had a degree in Education $(n=195)$ and only 38 teachers a Master's degree (16\%). Among in-service teachers, 29 taught Kindergarten (18\%), 64 Elementary Education (41\%), 46 Secondary Education (29\%), and 19 participants taught both Kindergarten and Elementary Education (12\%).

\subsection{Instruments}

To measure teachers' beliefs about diversity in its two dimensions, personal and professional, the Personal Beliefs about Diversity Scale and the Professional Beliefs about Diversity Scale (Pohan \& Aguilar, 1999) were used. Both scales include several statements referring to questions related to diversity such as race/ethnicity, gender, social class, sexual orientation, ability, language, immigration, and religion, this last one only in the professional beliefs scale. Respondents have to show through a 5-point Likert Scale (1= Strongly disagree; 5 = Strongly agree) the level of agreement for the different statements, both in personal and professional contexts.

The Personal Beliefs about Diversity Scale consists of 15 items, and the minimum and maximum scores range from 15 to 75, respectively. The Professional Beliefs about Diversity Scale consists of 25 items with scores that range from 25 to 125 . In both scales, low scores reflect a low tolerance towards diversity while high scores indicate a higher acceptance. Likewise, midrange scores can show a general tolerance towards some diversity issues or indifference (or uncertainty) for others. It may also reflect a high acceptance for some questions and a low acceptance for some other topics included in the measure (Pohan \& Aguilar, 2001).

The analysis of internal consistency showed an acceptable reliability for both scales. Cronbach's Alpha was .67 for the Personal Beliefs about Diversity Scale and .66 for the Professional Beliefs about Diversity Scale.

Together with both scales it was included an additional piece of information on socio-demographic data: gender, age, employment situation, years of teaching experience, 
qualifications, diversity and multicultural education courses received, contact and experience with diverse people, and number of languages spoken.

\section{$2.4 \quad$ Procedures}

To collect information it was requested the collaboration of teachers from different schools in the province of Alicante and students enrolled in a Master's degree on School Psychology at the University of Alicante. The instruments were delivered by hand and, after explaining the procedure, respondents who voluntarily agreed to participate were invited to complete the questionnaires in a two-week period. Confidentiality was guaranteed at all times and teachers were encouraged to answer as honestly as possible.

\subsection{Data analysis}

For the purposes of analysing the data in a meaningful way and in order to simplify the variety of categories related to diversity included in the instruments, the items of both scales were organised according to four categories, namely: (a) cultural, linguistic and social diversity, (b) ability, (c) gender, and (d) sexual orientation. The Professional Beliefs about Diversity Scale included a fifth category referring to religion, as indicated previously.

The data analyses were carried out with the statistical software, IBM SPSS Statistics (version 22). A series of analyses were performed in order to answer the four research questions. For the first research question, descriptive analyses were calculated to know teachers' personal and professional beliefs about diversity (i.e., mean, standard deviation). The second research question was analysed using a one sample t-test in order to determine in what diversity issues teachers show a higher or lower sensitivity. For the third research question, referring to differences in beliefs about diversity depending on the context (personal or professional), it was performed a paired sample ttest. Finally, the fourth research question related to differences in beliefs depending on teaching experience, a series of one-way between-groups analysis of variance (ANOVA) were carried out.

\section{RESULTS}

The results are presented in four sections accordingly to the four questions set out in the research. The first section shows descriptive analysis on teachers' personal and professional beliefs about diversity. The second section includes the level of sensitivity towards specific issues on diversity. The third section presents an analysis of the differences between personal and professional beliefs. Finally, in the fourth section teachers' beliefs are compared as a function of teaching experience.

\subsection{Personal and professional beliefs about diversity}

Table 1 shows the results obtained in the different categories set out from the items in the Personal Beliefs about Diversity Scale and the Professional Beliefs about Diversity Scale.

Regarding personal beliefs, respondents showed a high sensitivity towards diversity $(M=4.27, S D=0.35)$. In general, they valued favourably all the diversity aspects included in the instrument with a score higher than 4 . Issues related to sexual orientation, ability and gender were the best valued and the statements about cultural, linguistic and social diversity were less accepted.
With respect to professional beliefs, the general assessment was set lightly over the midpoint of the scale $(M=3.66, S D=$ 0.31). Respondents showed a higher sensitivity in aspects like sexual orientation and ability, while they were a little bit more undecided in questions related to cultural, linguistic and social diversity and religion. Unfavourable beliefs regarding gender were identified. The means and the standard deviations for each category are shown in table 1.

Table 1. Teachers' personal and professional beliefs about diversity

\begin{tabular}{lccccc}
\hline & \multicolumn{2}{c}{$\begin{array}{c}\text { Personal } \\
\text { beliefs }\end{array}$} & \multicolumn{2}{c}{$\begin{array}{c}\text { Professional } \\
\text { beliefs }\end{array}$} \\
Diversity Issues & $\boldsymbol{M}$ & $\boldsymbol{S D}$ & $\boldsymbol{M}$ & $\boldsymbol{S D}$ \\
\hline Cultural, linguistic and social diversity & 4.04 & 0.46 & 3.52 & 0.42 \\
Ability & 4.47 & 0.64 & 4.22 & 0.43 \\
Gender & 4.45 & 0.45 & 2.51 & 0.60 \\
Sexual orientation & 4.48 & 0.52 & 4.87 & 0.43 \\
Religion & - & - & 3.84 & 0.91 \\
TOTAL & 4.27 & 0.35 & 3.66 & 0.31 \\
\hline
\end{tabular}

\subsection{Level of personal and professional sensitivity towards diversity issues}

With the aim of determining which diversity issues were significantly higher or lower than the midpoint of the scale, a one sample t-test was carried out. A response level above and below of 3.5 was considered as a test value for the contrast. Results showed that from a personal point of view respondents had a relatively high sensitivity towards all the dimensions of diversity: cultural, linguistic and social $[t(232)=18.150, p<$ $.001]$, ability $[\mathrm{t}(232)=23.017, \mathrm{p}<.001]$, gender $[t(232)=$ 32.236, $p<.001]$ and sexual orientation $[t(232)=28.464, p<$ .001]. Professionally, they also showed a significant higher sensitivity towards questions related to ability $[t(231)=25.282$, $p<.001]$, sexual orientation $[t(232)=48.551, p<.001]$ and religion $[t(232)=5.716, p<.001]$, while gender was significantly lower than the test value $[t(232)=-25.027, p<$ .001]. No statistically significant differences were found for cultural, linguistic and social diversity $[t(231)=1.017, p<.310]$, results which were indicative of a respondent neutral or undecided position when referring to these questions (see table 2).

Table 2. Levels of personal and professional sensitivity towards diversity

\begin{tabular}{|c|c|c|c|}
\hline & $\begin{array}{c}\text { Significantly } \\
\text { lower than } 3.5\end{array}$ & Undecided & $\begin{array}{c}\text { Significantly higher } \\
\text { than } 3.5\end{array}$ \\
\hline $\begin{array}{l}\text { Personal } \\
\text { beliefs }\end{array}$ & & & $\begin{array}{l}\text { Cultural, linguistic } \\
\text { and social diversity } \\
\text { Ability } \\
\text { Gender } \\
\text { Sexual orientation }\end{array}$ \\
\hline $\begin{array}{l}\text { Professional } \\
\text { beliefs }\end{array}$ & Gender & $\begin{array}{l}\text { Cultural, linguistic } \\
\text { and social diversity }\end{array}$ & $\begin{array}{l}\text { Ability } \\
\text { Sexual orientation } \\
\text { Religion }\end{array}$ \\
\hline
\end{tabular}




\subsection{Differences between personal and professional beliefs about diversity}

In order to know how teachers' personal and professional beliefs about diversity differ, it was carried out a paired sample t-test. The results showed statistically significant differences between these two domains $[t(230)=24.47, p<.01]$. Respondents showed a higher sensitivity towards diversity in their personal scope $(M=4.27, S D=0.35)$ than in their professional scope $(M$ $=3.66, S D=0.31$ ).

When comparing personal and professional beliefs by category, statistically significant differences at the level of $p<$ .001 were found in all of them. Teachers' acceptance of diversity was higher from a personal than from a professional point of view in statements related to cultural, linguistic and social diversity $[t(231)=14.424, p=.000]$, ability $[t(231)=5.301, p=$ $.000]$ and gender $[t(232)=43.715, p=.000]$. However, in aspects related to sexual orientation, respondents showed more favourable beliefs when considered from a professional $(M=$ $4.87, S D=0.43)$ than from a personal view $[M=4.48, S D=$ $0.52, t(232)=-10.107, p=.000]$.

\subsection{Differences between personal and professional beliefs depending on teaching experience}

To answer the fourth research question two one-way betweengroups ANOVAs were carried out, one for each scale. For this purpose, the independent variable "years of teaching experience" was transformed into four levels (1: 0 years; 2: 1-6 years; 3: 7-14 years; $4: \geq 15$ years). The analysis of variance revealed statistically significant differences in teachers' professional beliefs about diversity $[F(3,214)=24.05, p<.01)]$. The effect size using eta squared was high (.25). Post-hoc comparisons using Scheffé test showed that these differences happened between the group with no teaching experience $(M=97.77, S D$ $=6.20)$ and those with one to six years of experience $(M=$ $90.68, S D=6.67)$, between seven and 14 years of teaching experience $(M=88.59, S D=7.23)$ and those with 15 or more years of experience $(M=88.37, S D=8.04)$. Teachers with no teaching experience showed a higher tolerance towards diversity in the professional context than the rest of the groups. Regarding personal beliefs, no statistically significant differences were found $[F(3,216)=0.003, p=1.000]$.

A more detailed analysis by categories showed that these differences in professional beliefs about diversity were statistically significant in: cultural, linguistic and social diversity $[F(3,215)=18.25, p<.001)]$, ability $[F(3,215)=6.42, p<$ $.001)]$ and gender $[F(3,216)=14.41, p<.001)]$. Besides the statistical significance, the effect size using eta squared was medium and high for the three categories (table 3). In all cases, respondents with no years of teaching experience showed more favourable beliefs towards diversity than experienced teachers.

\section{DISCUSSION AND CONCLUSIONS}

The purpose of this study was to examine the personal and professional beliefs that teachers hold about diversity, as well as their relationship to teaching experience. Overall, teachers show a high sensitivity towards the diversity issues addressed in the study (cultural, linguistic and social diversity, ability, gender, sexual orientation and religion), both from a personal and a professional perspective. Other studies carried out using Pohan \& Aguilar's scales (1999) show similar results to those of the present study, with item scores generally over the midpoint of the scale (Cardona, 2005; Pohan, 1995; Su-Chuan, 2009). In general terms, it can be said that respondents keep a belief system that favours multicultural education and attention to diversity, which is positive for theoretical and practical pedagogical considerations.

The various diversity issues addressed in the study were examined more deeply, and results showed a teachers' higher sensitivity towards these issues from a personal than from a professional perspective. In fact, from a personal perspective participant teachers got scores significantly higher than the test value of 3.5 in aspects related to cultural, linguistic and social diversity, ability, gender and sexual orientation. However, they were more tolerant towards questions like ability, sexual orientation and religion, and more neutral or indifferent in regards to cultural, linguistic and social diversity when these issues were analysed from a professional view. Finally, the topics related to gender were the less valued within the frame of a professional context. These results give support to a lower tolerance or acceptance of this aspect of diversity as have already been reported in the studies of Giambo and Szecsi (2007) and of Chiner and Bravo (2013).

Overall, the results of the current study suggest what other studies already indicated (e.g., Giambo \& Szcesi, 2007; Pohan \& Aguilar, 2001; Su-Chuan, 2009): although there is a clear relationship between personal and professional beliefs about diversity, significant differences between them in specific aspects exist. In general, teachers show a higher sensitivity in the personal context than in the professional one. In fact, these differences were found in all the categories with the exception of sexual orientation, aspect in which teachers showed a higher tolerance from a professional than from a personal view.

Considering Richardson's theory (1996) that states that the belief system is developed through experience and that by the moment of entering college it is already formed, Giambo \& Szecsi (2007) state that teachers' personal beliefs about diversity are more positive than professional beliefs because teachers have usually been exposed along the years to vital experiences that have modelled them. Nevertheless, professional beliefs would not be developed yet because of the lack of educational experiences to shape them. This explanation, however, is not sufficient to justify the teachers' personal and professional differences in beliefs found in the current study. Unlike other studies (e.g., Chiner \& Bravo, 2013; Giambo \& Szecsi, 2007;

Tabla 3. Effects of teaching experience on teachers' professional beliefs about diversity (One-way ANOVA)

\begin{tabular}{|c|c|c|c|c|c|c|c|c|c|c|c|c|}
\hline \multirow[t]{2}{*}{ Diversity Issues } & \multicolumn{2}{|c|}{0 years } & \multicolumn{2}{|c|}{ 1-6 years } & \multicolumn{2}{|c|}{ 7-14 years } & \multicolumn{2}{|c|}{$\geq 15$ years } & \multirow[b]{2}{*}{$\boldsymbol{F}$} & \multirow[b]{2}{*}{ gl } & \multirow[b]{2}{*}{$p$} & \multirow[b]{2}{*}{$\eta^{2}$} \\
\hline & $M$ & $S D$ & $M$ & $S D$ & $M$ & $S D$ & $M$ & $S D$ & & & & \\
\hline Cultural, linguistic and social diversity & 49.70 & 4.12 & 45.64 & 4.47 & 44.02 & 4.61 & 44.67 & 5.53 & 18.255 & 3,215 & .000 & .20 \\
\hline Ability & 26.54 & 2.29 & 25.23 & 2.62 & 24.92 & 2.67 & 24.70 & 2.67 & 6.422 & 3, 215 & .000 & .08 \\
\hline Sexual orientation & 13.66 & 1.32 & 13.74 & 1.73 & 13.24 & 1.64 & 13.19 & 1.76 & 1.715 & 3, 216 & .165 & .02 \\
\hline Gender & 8.54 & 1.70 & 7.43 & 1.77 & 7.31 & 1.56 & 6.57 & 1.66 & 14.407 & 3, 216 & .000 & .16 \\
\hline Religion & 8.19 & 1.36 & 7.55 & 1.92 & 7.37 & 1.87 & 7.61 & 1.98 & 2.460 & 3, 216 & .000 & .03 \\
\hline
\end{tabular}


Schroeder, 2005), where only pre-service teachers participated, in this research we counted on the participation of both, inservice and pre-service teachers. This allowed to compare both groups' beliefs. Taking this into account, it would be possible to think that less favourable professional beliefs about diversity can be caused not only because of the lack of school experience, but, indeed, because of the experience. When we studied the differences between personal and professional beliefs taking into account the years of teaching experience, a clear discrepancy between teachers with experience and those that have not worked as teachers yet were observed. The latters showed more positive professional beliefs than teachers with higher experience, while from a personal view differences were not found. These results are similar to those found by Cardona (2005) and seem to suggest that teachers, before entering the field, have developed a belief system that favours respect and attention to diversity in the classrooms. Nevertheless, the more experience they acquire, the less sensitive towards diversity they are, indicating that teachers show more favourable beliefs towards diversity in theory than in practice. Given that beliefs can have a direct impact on teachers' educational practices and on the response they give to the students with diverse needs (Bandura, 1982; Brookhart \& Freeman, 1992; Pajares, 1992), it would be necessary to investigate about the reasons that lead teachers to show lower levels of sensitivity in educational contexts, while their personal beliefs keep positive. Factors like the lack of resources, supports or an ongoing training focused on the pedagogical implications of diversity (Chiner \& Cardona, 2013) could be the basis to change these beliefs. Therefore, future research should be oriented to analyse these and other factors, and implement interventions to promote the development of a belief system that favours multicultural education and attention to diversity.

Most of the studies carried out about the topic have focused on investigating the impact that multicultural education courses have on teachers' personal and professional beliefs (e.g., Pohan \& Aguilar, 2001; Romine, 2010; Su-Chuan, 2009), however, this research focused on pre-service teachers. Future works should, therefore, analyse the effect of these courses on in-service teachers as well, with the purpose of moving on from theory to practice. That is, moving from an initial training, mostly focused on theoretical and philosophical approaches about diversity, to an ongoing training with emphasis on the pedagogical implications of diversity.

The results achieved in this study are not exempt from certain limitations related to the methodology used that can make difficult its generalization to other contexts and subjects. Apart from the use of the survey, it would be convenient to use other data collection techniques like observation or interview which would help to go more deeply into participants' responses. Those techniques would provide a greater understanding of teachers' dispositions towards diversity and would counteract the effect that social desirability may have on participants' answers.

In spite of this, the current study has allowed to identify teachers' beliefs towards diversity issues and can be used as a starting point for further research. It is especially notable the need for teachers to be able to recognise the existing differences between the personal and professional views on diversity. In addition, a good planning and the development of intervention programmes addressed to in-service teachers that favour a higher awareness and sensitivity towards difference and its impact on education would allow a more effective entry in the teaching profession and, as a result, a better students' achievement.

\section{REFERENCES}

Ajzen, I., \& Fishbein, M. (1980). Understanding attitudes and predicting social behavior. Englewood Cliffs, NJ: Prentice-Hall.

Bandura, A. (1982). Self-efficacy mechanism in human agency. American Psychologist, 37(2), 122-147. doi: 10.1037/0003-066X.37.2.122

Banks, J. A., \& Banks, C. A. M. (2007). Multicultural education: issues and perspectives ( $6^{\text {th }}$ ed.). New York, NY: Wiley.

Brookhart, S. M., \& Freeman, D. J. (1992). Characteristics of entering teacher candidates. Review of Educational Research, 62(1), 37-60. doi: 10.3102/00346543062001037

Cardona, M. C. (2005, April). Assessing teachers' beliefs about diversity in personal and professional contexts. Paper presented at the Annual Meeting of the American Educational Research Association, Montreal, Canada.

Cardona, M. C., \& Chiner, E. (2002, September). Spanish teachers' personal and professional beliefs about diversity: is there any difference? Paper presented at the European Conference on Education Research, Lisbon, Portugal.

Cardona, M. C., Jiménez, C., \& Chiner, E. (2007). ¿Son los profesores tolerantes con las diferencias? Análisis de sus actitudes e implicaciones en el proceso de la convergencia europea. In R. Roig Vila, J. Blasco, M. A. Cano, R. Gilar, S. Grau, \& A. Lledó (Eds.), Investigar el cambio curricular en el Espacio Europeo de Educación Superior (pp. 77-90). Alcoy, Spain: Marfil.

Chiner, E., \& Bravo, L. I. (2013). Estudio sobre las creencias personales y profesionales de los alumnos de psicopedagogía acerca de la diversidad. In M. C. Cardona, E. Chiner \& A. Giner (Eds.), Investigación e innovación educativa al servicio de instituciones y comunidades globales, plurales y diversas. Alicante, Spain: AIDIPE.

Chiner, E., \& Cardona, M. C. (2013). Inclusive education in Spain: how do skills, resources, and supports affect regular education teachers' perceptions of inclusion? International Journal of Inclusive Education, 17(5), 526-541. doi: 10.1080/13603116.2012.689864

Fernández Batanero, J. M. (2003). Cómo construir un currículum para «todos»los alumnos. Granada, Spain: GEU.

Giambo, D., \& Szecsi, T. (2007). Does diversity education make a difference in teacher education? Practice and Theory in Systems of Education, 2(3-4), 35-50.

Hansman, C. A., Jackson, D. F., Grant, D. F., \& Spencer, L. E. (1999). Assessing graduate students' sensitivity to gender, race, equity and diversity: implication for curriculum development. College Student Journal, 33(2), 261-268.

Hinojosa, M. S., \& Moras, A. B. (2009). Challenging colorblind education: a descriptive analysis of teacher racial attitudes. Research and Practice in Social Sciences, 4(2), 27-45.

Hollins, E. R., \& Guzman, M. T. (2005). Research on preparing teachers for diverse populations. In M. Cochran-Smith \& K. M. Zeichner (Eds.), Studying teacher education: The report of the AERA panel on research and teacher education (pp. 477-513). Mahwah, NJ: Lawrence Erlbaum Associates.

Larke, P. J. (1990). Cultural Diversity Awareness Inventory: assessing the sensitivity of preservice teachers. Action in Teacher Education, 9(3), 23-30. doi: 10.1080/01626620.1990.10734396

Milner, R., Flowers, L, Moore, E., Moore, J., \& Flowers, T. (2003). Preservice teachers' awareness of multiculturalism and diversity. The High School Journal, 87(1), 63-70. doi: 10.1353/hsj.2003.0018

Nespor, J. (1987). The role of beliefs in the practice of teaching. Curriculum Studies, 19(4), 317-328. doi: 10.1080/0022027870190403

Neuharth-Pritchett, S., Reiff, J., \& Pearson, C. (2001). Through the eyes of preservice teachers: implications for multicultural journal from teacher education. Journal of Research in Childhood Education, 15(2), 256-270. doi: 10.1080/02568540109594965

Pajares, M. F. (1992). Teachers' beliefs and educational research: Cleaning up a messy construct. Review of Educational Research, 62(3), 307-332. doi: $10.3102 / 00346543062003307$

Pohan, C. A. (1995). The development and validation of the educators' beliefs about diversity scale (Doctoral dissertation). Retrieved from Proquest Dissertations and Theses (UMI No. 9507822).

Pohan, C. A., \& Aguilar, T. E. (1999). The personal and professional beliefs about diversity scales: User's manual and scoring guide. Unpublished document.

Pohan, C. A., \& Aguilar, T. E. (2001). Measuring educators' beliefs about diversity in personal and professional contexts. American Educational Research Journal, 38(1), 159-182. doi: 10.3102/00028312038001159

Pohan, C. A., Ward, M., Kouzekanani, K., \& Boatright, C. (2009). The impact of field placement sites on preservice teachers' beliefs about teaching diverse students. School-University Partnerships, 3(1), 43-53.

Richardson, V. (1996). The role of attitude and beliefs in learning to teach. In J. Sikula, T. Buttery \& E. Guyton (Eds.), Handbook of research on teacher education ( $2^{\text {nd }}$ ed., pp. 102-119). New York, NY: Macmillan.

Romine, X. (2010). The relationship of personal and professional teacher diversity belief typologies to average student mathematics achievement in middle schools serving the diverse populations of North Georgia (Doctoral dissertation). Retrieved from Proquest Dissertations and Theses (UMI No. 3439784). 
Shroeder, M. C. (2005). The relationship between educators' personal and professional beliefs about diversity: cross-cultural experiences and multicultural coursework as predictors of sensitivity (Doctoral dissertation). Retrieved from Proquest Dissertations and Theses (UMI No. 3318746).

Su-Chuan, H. (2009). Meeting the challenges of diversity: beliefs of Taiwanese preservice early childhood teachers (Unpublished doctoral dissertation). University of North Texas, Denton, TX. 